\title{
Physical, chemical and biological responses to simulated wind and tidal mixing in experimental marine ecosystems
}

\author{
Percy L. Donaghay \& Eric Klos
}

Graduate School of Oceonography, University of Rhode Island, Narragansett, Rhode Island 02882, USA

\begin{abstract}
Vertical mixing processes and resulting physical structures may influence dynamics of marine ecosystems. Knowledge of the ecological significance of mixing processes has been restricted by our lack of ability to control and manipulate these factors experimentally. A technique is described that permits development and maintenance of 2-layered stratification in land based mesocosms. A variety of vertical physical structures and mixing regimes within and between layers can be simulated which are typical of various parts of the marine environment. In an initial experiment, replicate, stable multi-trophic level model ecosystems developed and maintained themselves for $2 \mathrm{mo}$. The biological replicability and ability of the system to support multiple trophic levels including zooplankton and ctenophore predators over long periods of time suggests that these systems have onsiderable promise for analysis of effects of mixing and spatial heterogenity on the dynamics of coastal marine ecosystems.
\end{abstract}

\section{INTRODUCTION}

Vertical mixing processes and the resulting vertical density structure are critical to both the dynamics and the structure of marine ecosystems. For example, field studies comparing vertically-stratified, well-mixed, and frontal zones in the English Channel have shown that both the dynamics and composition of the ecosystems are affected by vertical mixing (Holligan et al. 1984). Conceptual models of the dynamics of planktonic ecosystems have emphasized the importance of vertical structure in regulating phytoplankton species composition and primary production processes (Margalef 1978, McCarthy \& Carpenter 1983), zooplankton community dynamics (Steele \& Henderson 1981), and the development of major oceanographic features such as patchiness (Evans 1978, Kullenberg 1978).

Although field studies have strongly suggested that vertical mixing processes are important to ecosystem structure, it has been very difficult to separate the effects of vertical mixing from those of temperature, salinity, lateral advection, and water mass history Mesocosms (Banse 1982) lend themselves to this type of study as they permit experimental manipulation on an ecosystem scale. However, surprising little work on experimental manipulation of mixing regimes has been carried out so far, although the results of these few experiments have been encouraging. Comparison of mixed and unmixed mesocosms (Eppley et al. 1978, Oviatt 1981) have shown that mixing alters the structure and function of the ecosystems. However, no attempt has been made so far to mimic turbulent energy input either to wind-mixed surface layers or tidally-mixed bottom layers. Thus, as the typical physical environments generated by these energy input processes have not yet been replicated experimentally, their role in shaping community structure and dynamics has accordingly not been studied adequately. In this paper we describe a series of techniques that have been successfully employed to establish and maintain stratification in $5 \mathrm{~m}$ deep, $13 \mathrm{~m}^{3}$ volume tanks located at the Marine Ecosystems Research Laboratory of the University of Rhode Island. These experimental marine ecosystems or mesocosms are located on the shores of Narragansett Bay, Rhode Island (Pilson \& Nixon 1980). These systems have been used for more than 8 yr to study the fate and effect of pollutants (Oviatt et al. 1982), biogeochemical cycles (Santschi 1982) and the effects of nutrients on ecosystem dynamics (Nixon et al. 1984). Most previous studies have been carried out with well-mixed water columns where mixing was maintained by a plunger 
system (Nixon et al. 1980). Oviatt (1981) described an experiment where weak stratification was obtained by not mixing the systems. Herein, we describe a series of techniques that allow experimental manipulation of mixing processes and vertical physical structure. The response of the enclosed natural plankton community to these stratified conditions are also described and compared to the responses in well-mixed mesocosms and to well-mixed and stratified field systems.

\section{MATERIALS AND METHODS}

Development and maintenance of stratification. Two-layered mesocosms were established in 2 MERL tanks (Fig. 1). Mechanical changes in the design of the mixer and temperature control system (both described below) were made to meet 5 primary developmental objectives (Table 1). In addition, all system components in contact with seawater in the tanks had to be non-toxic, easy to remove and clean, and nondisruptive to the plankton community (i.e. movement of a mixer should not cause animal escape response or cessation of feeding by herbivores or carnivores).

The desired temperature structure was achieved by only minor changes in the previous temperature control system, which consisted of a glass heat exchanger hung at the top of the tank. In the stratified system, 2 heat exchangers chilled with ethylene glycol to $1{ }^{\circ} \mathrm{C}$ were hung near the bottom of the tank of develop a cold lower layer. Manual control of the flow of coolant was sufficient to control lower-layer temperature to $\pm 1 \mathrm{C}^{\circ}$ of the desired temperature. Solar heating of the surface layer, coupled with heat exchange across the
Table 1. Developmental objectives

(1) Establish a stratified system with well-mixed surface and bottom layers separated by a temperature and/or salinity induced pycnocline

(2) Develop a system to control thermal structure and mixing rates within and between layers

(3) Maintain strong chemical and biotic gradients across the pycnocline

(4) Maintain viable planktonic communities in both layers for more than 1 mo

(5) Develop surface layer planktonic communities dominated by internal recycling and cross-thermocline transport processes

thermocline, were sufficient to maintain surface temperature of $20 \pm 1^{\circ} \mathrm{C}$ and the desired cross-thermocline temperature differentials. While surface-layer solar heating and bottom-layer chilling were adequate to control temperature during the summer when our experiment was run, operation in other seasons would require development of surface layer temperature control systems that could adequately respond to the rapid fluctuations in thermal inputs to, and losses from, the surface layer typical of those seasons.

A new mixer system was developed to control mixing within and between layers. In well-mixed mesocosms, a vertical plunger stirrer mixed the water column in 15 min (Nixon et al. 1980). In order to replace the normal vertical motion with horizontal rotary motion, the mixer motors were repositioned $90^{\circ}$ and centered over the tanks. The motor shaft was extended to near the bottom of the tank with a PVC pipe to which mixing paddles were attached. Two styles of mixing paddles were developed to provide varying degrees of

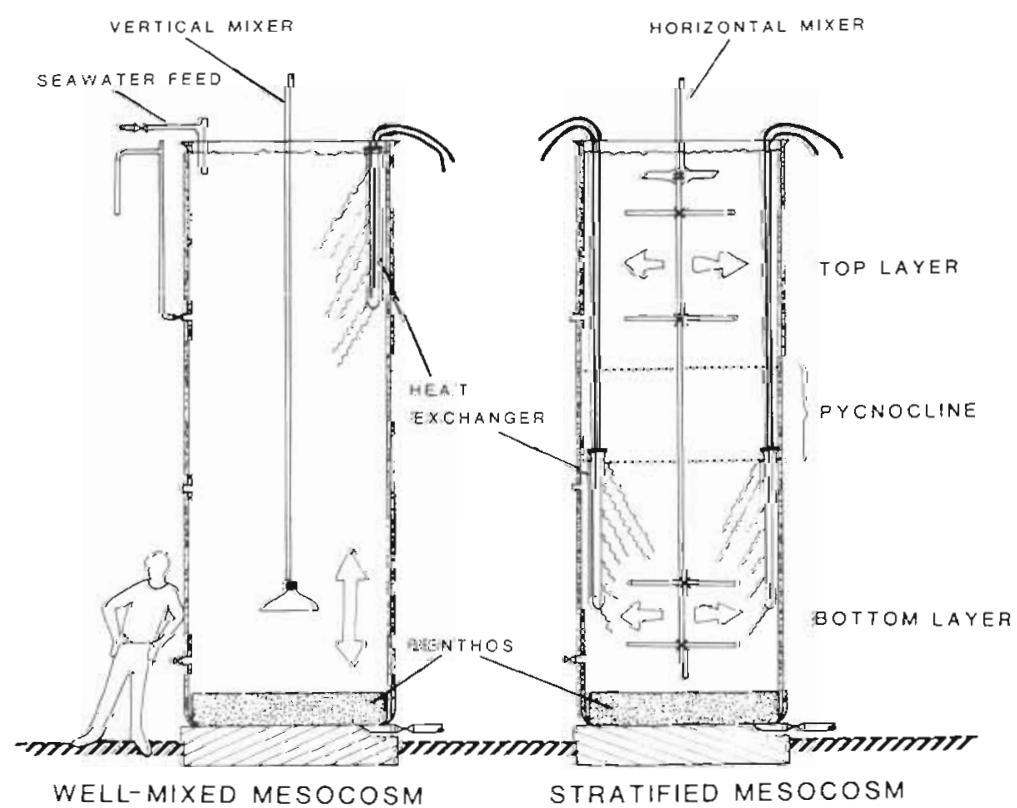

Fig. 1. Comparison of mechanical design of well-mixed and stratified MERL mesocosms. See text for description of hardware components 
mixing. Paddles made of $2.5 \mathrm{~cm}$ diameter, $1 \mathrm{~m}$ long pieces of PVC pipe were used to provide most of the mixing. Variation of the number and position of these pipe paddles was used to control the distribution of turbulent energy input into the 2 layers of the stratified system. A propeller type paddle was developed to provide the higher turbulent energy input (at a given mixer speed) required to maintain isothermal conditions at the surface of the mesocosm. The propeller paddle was constructed of $7.5 \mathrm{~cm}$ wide by $65 \mathrm{~cm}$ long by $1 \mathrm{~cm}$ thick PVC plate twisted in the middle to provide two $30 \mathrm{~cm}$ long blades rotated $45^{\circ}$ to the mixer shaft and $90^{\circ}$ to each other.

A new mixing controller was also developed for the stratified mesocosms. In the well-mixed mesocosms, a single controller provided a schedule of $2 \mathrm{~h}$ of vertical mixing at 5 plunger strokes $\min ^{-1}$ followed by $4 \mathrm{~h}$ of no mixing. For the stratified mesocosms, a separate controller was built to regulate mixer speed (rpm), rotational direction, length of total cycle, and the length of time in a cycle the mixer was on and off (Fig. 2). Operator selection of stirring sequences ranged from continuous rotation in 1 direction to repetitive cycles of equal intervals of clockwise and counterclockwise rotation separated by equal periods of no mixing. Continuous mixing was not used extensively since it resulted in rotation of the entire water column. The duration of the repetitive cycles could be varied by the operator from 1 to $99 \mathrm{~min}$. In initial studies, the controller was used to vary a variety of factors in order to evaluate their effect on controlling the intensity and dimensions of mixing. For most of the experiments reported herein, the cycle length was fixed at $12 \mathrm{~min}$ with the mixing schedule shown in Fig. 2b. In preliminary experiments, mixer speed was varied, but for the longer term experiments used to evaluate biological and chemical responses, mixing speed was fixed at 3.5 rpm.

Analytical methods. Vertical physical structure was determined using in situ probes and discrete depth samples. Temperature and salinity profiles were made daily using a conductivity, salinity and temperature probe (Model 33, Yellow Springs Instrument Co., Yellow Springs, Ohio). Discrete depth samples for salinity were collected by siphon and analysed on an inductive salinometer (Industrial Instruments, RS-7B). Vertical profiles of light were made periodically at noon by recording light at depth using a Lambda in situ probe (Model LI 185).

Vertical distribution of inorganic nutrients, $\mathrm{pH}$, chlorophyll a fluorescence, and phytoplankton species composition were determined from analysis of samples siphoned from discrete depths. All samples were siphoned through a $6 \mathrm{~mm}$ internal diameter teflon sampling tube using trace-metal-clean techniques
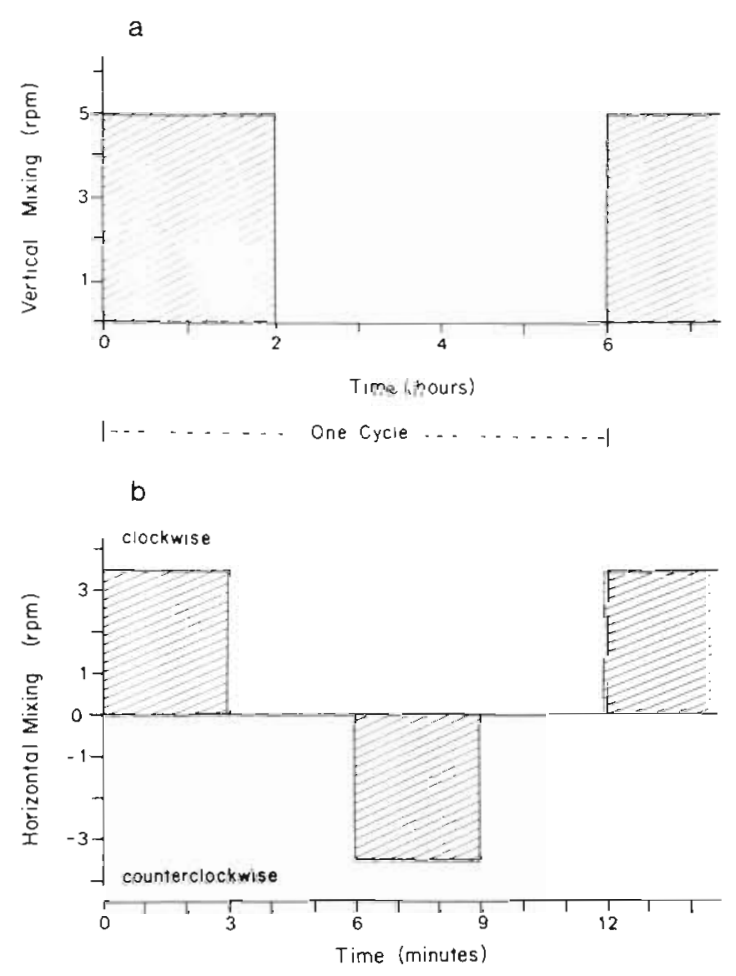

Fig. 2. Schedule of mixing in well-mixed mesocosm (a) and stratified mesocosms (b)

(Fox \& Kester 1985). Nutrient samples were immediately filtered using gentle pressure through prerinsed $0.45 \mu \mathrm{m}$ Nucleopore filters to remove particles. Samples were analysed using the procedure recommended by Friederich \& Whitledge (1972) on a 4 channel Technicon Autoanalyser II. Samples for $\mathrm{pH}$ were analysed using an Altex combination electrode and a Corning Model $111 \mathrm{pH}$ meter (Strickland \& Parsons 1968). Phytoplankton biomass was measured as chlorophyll a fluorescence on a Turner Model 111 fluorometer using a modification of the in vivo method of Lorenzen (1966). The modification involves normalizing all values to a coproporphyrin standard of known concentration (Sigma Chemical Co.). This procedure removed the effects of instrument drift (as recommended by G. K. Turner, pers. comm.).

Phytoplankton species composition was measured on $50 \mathrm{ml}$ subsamples siphoned from $1.5 \mathrm{~m}$ (surface layer), $2.5 \mathrm{~m}$ (pycnocline) and $3.5 \mathrm{~m}$ (bottom layer). A $2 \mathrm{ml}$ subsample was taken and transferred to a $3 \mathrm{ml}$ serum vial, preserved with 2 drops of Lugol's solution, and capped with a serum stopper. The remaining sample was placed in a refrigerator at $2{ }^{\circ} \mathrm{C}$ and live cell counts of flagellates and non-motile ultraplankton were made within $6 \mathrm{~h}$. The preserved samples were microscopically enumerated using the procedures of Venrick (1978a, b) and Guillard (1978). During the experiment, growth rates of the diatom Skeletonema 
costatum were measured in dialysis sacks suspended at $0.5 \mathrm{~m}$ in the surface layer. Growth rates were determined based on sequential samples from the dialysis sacks counted microscopically.

Zooplankton samples were collected by siphoning water through a $2.4 \mathrm{~cm}$ internal diameter polyethylene hose from either $1.5 \mathrm{~m}$ (surface layer) or $3.5 \mathrm{~m}$ (bottom layer). Flow rates with the siphon were equivalent to those with a pump (i.e. $501 \mathrm{~min}^{-1}$ ) and provided reproducible estimates of abundance. Zooplankton were removed from the siphoned water by collecting them on $150 \mu \mathrm{m}$ Nitex screening attached to a $20 \mathrm{~cm}$ diameter, $40 \mathrm{~cm}$ high plexiglass cylinder. This cylinder was placed in the bottom of a $75 \mathrm{l}$ polyethylene container. After a predetermined volume had filled the container, the siphon was stopped, and the screen with the zooplankton was removed. The water from the large container was returned to the layer from which it came by raising the container and reversing the siphon flow. The zooplankton on the screen were used for either biomass or species composition measurements. For biomass, zooplankton were rinsed with dionized water into preweighed vials, freeze dried, and weighed on a Mettler electrobalance (Model H31 AR). Samples for microscopic enumeration were preserved in buffered formalin and counted to species.

\section{RESULTS}

\section{Vertical physical structure and mixing characteristics}

A variety of vertical temperature structures were achieved by varying the number, position and type of paddles, the speed of stirring, and the position of the heat exchangers (Fig. 3). In the absence of any mixing, cooling of the bottom layer resulted in a thermocline spread over most of the water column (Fig. 3a). A strong stable thermocline with well-mixed top and bottom layers (Fig. 3c) was achieved with continuous chilling of the bottom layer and with the mixing paddle configuration shown in Fig. 1 b run at 3.5 rpm with the mixing schedule in Fig. $2 \mathrm{~b}$. The addition of salt to the bottom layers of identically configured systems allowed the development of stable thermohaline stratified systems with similar structure (Fig. 3d). The position and thickness of the pycnoclines were controlled by the position of the lower mixing paddle in the upper layer and the top of the chiller in the lower layer. The maximum compression of the thermocline achieved was $11^{\circ} \mathrm{C}, 2 \%$ differential across a $0.3 \mathrm{~m}$ pycnocline (Fig. $3 \mathrm{~d}$ ). This is equivalent to a 3.2 sigma theta density differential in $0.3 \mathrm{~m}$.

Mixing within and between layers was varied by altering the speed of stirring, the stirring cycle, and the
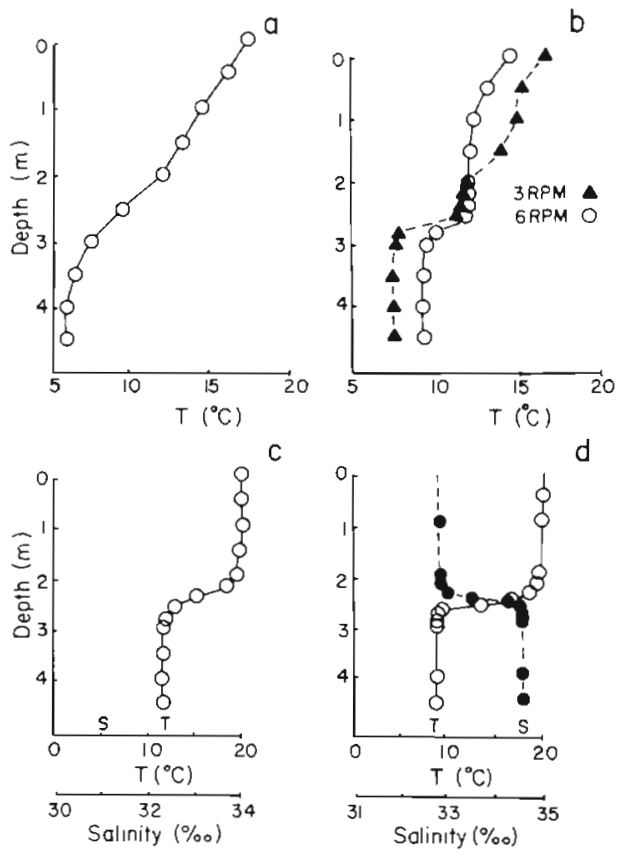

Fig. 3. Vertical profiles of temperature and salinity (salinity vertically constant except in Fig. 3d) under different mixing and stirring conditions: (a) temperature structure resulting from bottom cooling without mixing; (b) change in temperature structure resulting from increasing mixing speed from 3 to $6 \mathrm{rpm}$ for $24 \mathrm{~h}_{i}$ (c) vertical temperature structure resulting from mixing with stirer design shown in Fig. $1 \mathrm{~b}$ at $3.5 \mathrm{rpm}$ with mixing schedule shown in Fig. 2b; (d) vertical temperature and salinity structure in thermohaline stratified system with same mixing regime as in (c). Vertical structure in the 6 rpm mesocosm was identical to that in the $3 \mathrm{rpm}$ mesocosm prior to the initiation of $6 \mathrm{rpm}$ mixing, thus differences in vertical structure are a direct result of enhanced mixing rates generated by 6 rpm stirring

number, position and style of paddles used. Mixing between layers was varied by altering the speed of stirring. For example, increasing the speed from 3 to 6 rpm resulted in an increase in cross-thermocline mixing from less than $3 \% \mathrm{~d}^{-1}$ to greater than $40 \% \mathrm{~d}^{-1}$ (based on heat budget calculations, Fig. 3b). The effectiveness with which a single paddle configuration provided mixing within a layer was increased by increasing mixing speed (for example, compare the surface layer profiles in Fig. 3b). Mixing within a layer could be controlled independently of between-layer mixing by varying the position and style of paddles. For example, the propeller paddle in the surface layer stirrer configuration (Fig. 1b), allowed maintenance of $1 \% \mathrm{~d}^{-1}$ cross-thermocline mixing rates (Fox \& Kester 1985) and a well-mixed surface layer when run at 3.5 rpm (Fig. 3c, d); replacement of this propeller paddle with a pipe paddle resulted in surface stratification even when stirrers were run at higher speeds (Fig. 3b).

Although the technique for establishing stratified mesocosms allowed development of a variety of physi- 
cal structures (Fig. 3), the systems have been operated so far in 2 modes sufficiently long to allow definition of resulting vertical and temporal chemical and biotic responses. These 2 physical modes are (1) a moderately stratified system composed of 2 well-mixed layers separated by a weak thermocline $\left(7 \mathrm{C}^{\circ}\right.$ differential spread over $1 \mathrm{~m}$ ) (Fig. 4a), and (2) a strongly stratified system composed of 2 well-mixed layers separated by a strong pycnocline $\left(11 \mathrm{C}^{\circ}\right.$ plus $2 \%$ salinity differential spread over $0.3 \mathrm{~m}$, Fig. 4c). Mixing in all of these experiments was provided by running the mixer configuration shown in Fig. 1b at the speed and schedule shown in Fig. 2b.
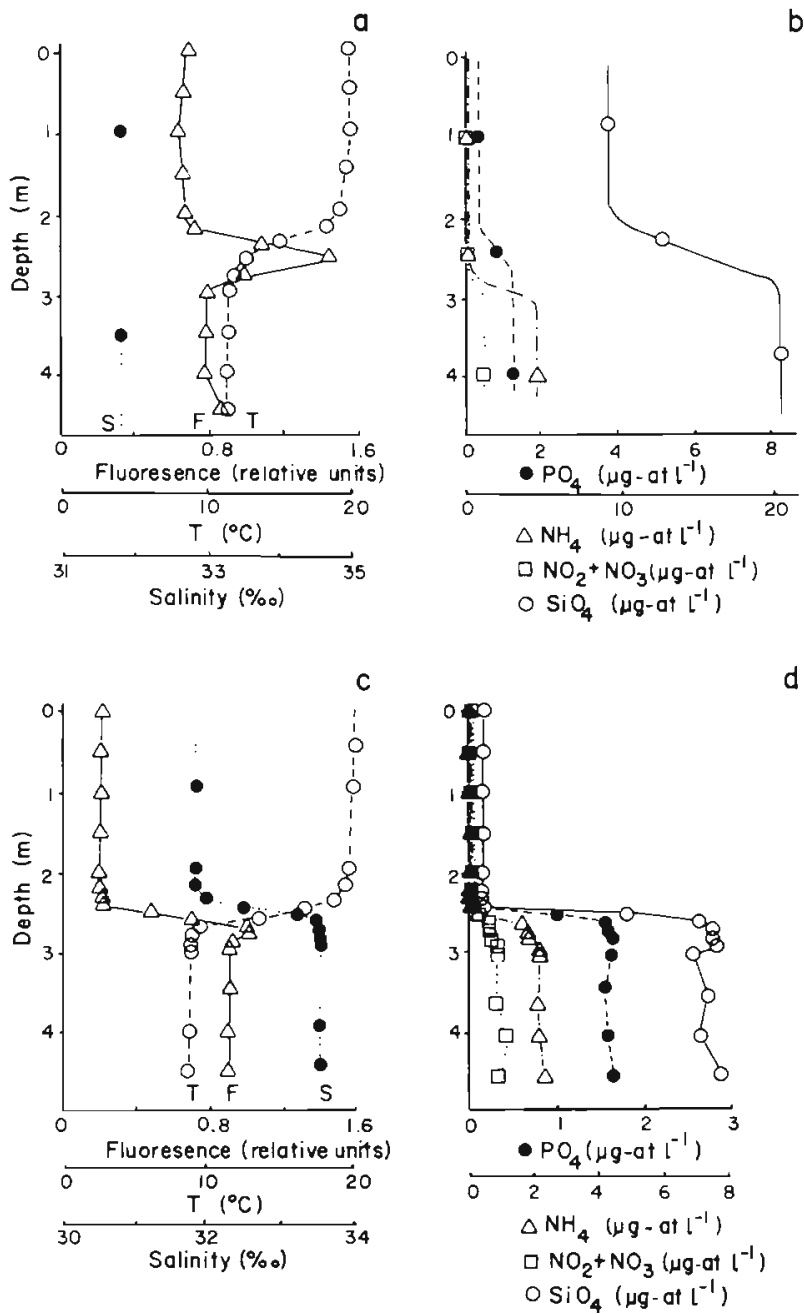

Fig. 4. Vertical physical, phytoplankton and nutrient structure observed in stratified systems. In both systems the mixer design in Fig. 1b was run with the mixing schedule in Fig. 2b. Vertical structures in the thermally stratified $(a, b)$ systems were measured after $1 \mathrm{wk}$ of operation. Structures shown in the thermohaline stratified system $(\mathrm{c}, \mathrm{d})$ were measured after $56 \mathrm{~d}$ of operation. A similar pattern had developed by Day 5 of operation

\section{Chemical gradients}

A strong nutricline developed in the stratified tanks after several days (Fig. 4b, d). Inorganic nitrogen (as $\mathrm{NO}_{3}, \quad \mathrm{NO}_{2}, \quad \mathrm{NH}_{3}$ ) rapidly declined to undetectable levels in the surface layer. Silicate was also reduced to very low but still detectable levels in the surface of the thermohaline system (Fig. 4d). In the thermally stratified system (Fig. 4b) silicate remained relatively high in the surface layer, but a strong $\mathrm{SiO}_{4}$ gradient occurred in the pycnocline. The combination of benthic regeneration of nutrients and lower primary production was sufficient to maintain easily detectable levels of $N, P$, and $\mathrm{Si}$ in the bottom layer. The nutricline that developed in the strongly stratified system was very sharp (order of magnitude change in $0.2 \mathrm{~m}$ ). In these systems, the maximum gradients in nutrients, phytoplankton fluorescence, and $\mathrm{pH}$ coincided and occurred in the upper part of the pycnocline (Fig. 5). Some small scale structures were observed within the pynocline in term of nutrients $\left(\mathrm{NO}_{2}+\mathrm{NO}_{3}, \mathrm{SiO}_{4}\right)$ and chlorophyll a fluorescence.

Stratification significantly altered light penetration in the mesocosms. Both surface and bottom layers had lower extinction coefficients than in well-mixed systems (Table 2). The lower extinction coefficients of the surface layer were the results of reduced phytoplank-

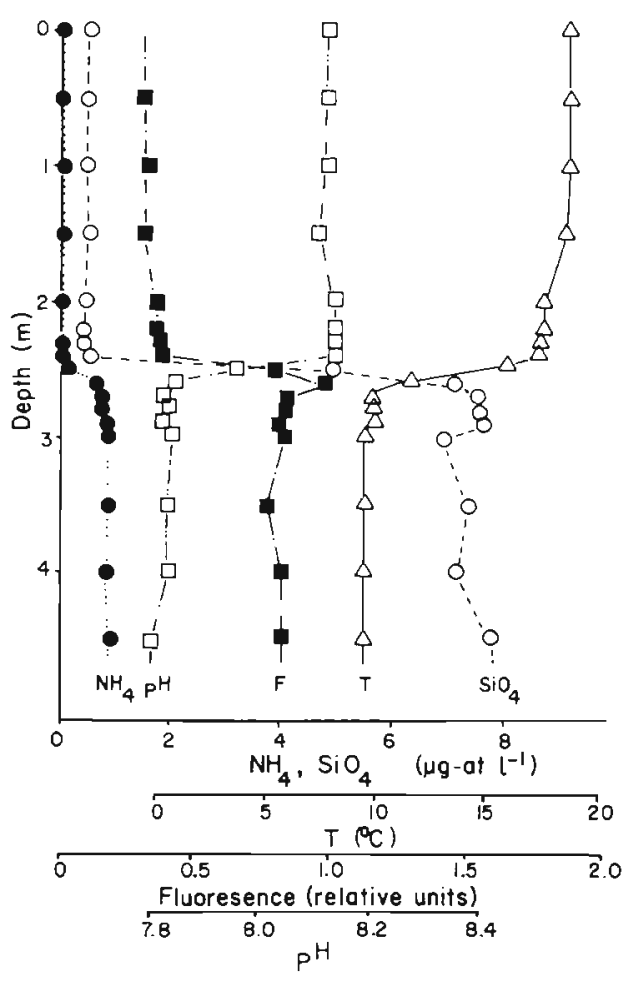

Fig. 5. Comparison of vertical profiles of temperature, $\mathrm{pH}$, $\mathrm{NH}_{4}, \mathrm{SiO}_{4}$ and chlorophyll fluorescence in the stratified tank after $56 \mathrm{~d}$ of operation 
Table 2. Extinction coefficients on 15 July 1981, from exponential curve fits to light data measured at specific depths at noon. Average refers to curves using all data; surface and bottom refer to only data taken from those well-mixed layers. Regression coefficients $\left(\mathrm{r}^{2}\right)$ from all analyses exceed 0.998 . Enriched $4 \mathrm{X}$ and $32 \mathrm{X}$ refer to well-mixed mesocosms run at the same time but with nutrients being added daily (see Donaghay 1984 for description)

\begin{tabular}{|llc|}
\hline Mesocosm & \multicolumn{1}{c}{ Layer } & $\begin{array}{c}\text { Extinction } \\
\text { coefficient }\end{array}$ \\
\hline Stratified A & Surface & -0.61 \\
& $\begin{array}{l}\text { Bottom } \\
\text { Average }\end{array}$ & -0.80 \\
Stratified B & Surface & -0.70 \\
& Bottom & -.65 \\
Well-mixed control A & Average & -.70 \\
Well-mixed control B & Average & -0.94 \\
Well-mixed, nutrient & & -1.02 \\
enriched (4X) & Average & -1.54 \\
Well-mixed, nutrient & & -1.87 \\
enriched (32X) & Average & \\
\hline
\end{tabular}

ton abundances and reduced resuspended particulate materials. Sufficient light reached the lower layer to permit photosynthesis and net growth of diatoms.

\section{Phytoplankton response}

Two types of phytoplankton biomass distribution were observed that correlated with different degrees of vertical stratification. In moderately-stratified systems, fluorescence maxima developed along the thermocline (Fig. 4a). The thickness of the chlorophyll a fluorescence maxima appeared to be regulated by the thickness of the pycnocline. The fluorescence maximum shown in Fig. 4a was maintained for $2 \mathrm{wk}$. In strongly stratified systems, no large fluorescence maxima were observed in the pycnocline, but fluorescence was uniformly high in the bottom layer (Fig. 4c). In such cases the thermocline was a transition zone of increasing fluorescence from very low values in the surface to moderate values in the lower layer. This type of structure was persistent in strongly-stratified mesocosms. The biomass differential between surface and bottom layers shown in Fig. 4c was about an order of magnitude in chlorophyll a (0.4 versus $\left.5.0 \mu \mathrm{g}^{-1}\right)$ and was maintained for 2 mo. Although both phytoplankton structures shown in Fig. 4 were reasonably stable once formed, the mechanism leading to these different distributions is not known.

In the strongly-stratified systems (Fig. 4c, d) phytoplankton responses were documented over a $3 \mathrm{wk}$

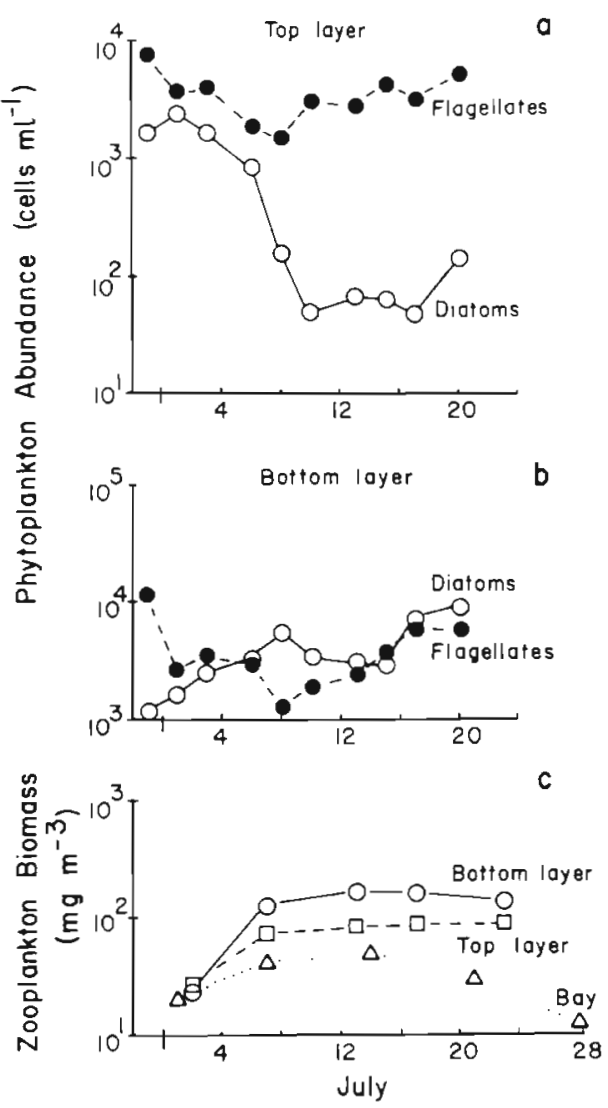

Fig. 6. Biological structure in the control stratified mesocosm during a 1 mo period

period. Flagellates responded to stratification by a rapid initial decline in abundance over the first $2 \mathrm{~d}$ followed by more or less stable abundances over the next 3 wk (Fig. 6). Flagellate abundances were not different between top and bottom layers (Fig. 6a, b). In contrast, diatoms showed strong differences between layers (Fig. 6a, b). In the surface layer, diatoms declined after the first few days in response to very low levels of silicate and nitrogen $\left(<0.01 \mu \mathrm{g}\right.$-at $\left.1^{-1}\right)$. In the lower layer, diatoms slowly but continuously increased over the entire $3 \mathrm{wk}$ period. After $2 \mathrm{wk}$ the abundance differences between the 2 layers were about 2 orders of magnitude.

\section{Zooplankton response}

Zooplankton biomass and numbers increased in response to stratification and remained remarkably stable (Fig. 6c). During the period of stable zooplankton biomass, zooplankton larger than $150 \mu \mathrm{m}$ (predominately copepodites and adults) averaged $20000 \mathrm{~m}^{-3}$ in the surface layer and $26000 \mathrm{~m}^{-3}$ in the bottom layer. These abundances are well above those observed in the well-mixed systems or Narragansett Bay at that time (Table 3). 
Table 3. Zooplankton adults and copepodites. Mean no. $\mathrm{m}^{-3} \pm \mathrm{SD}$

\begin{tabular}{|c|c|c|c|c|c|}
\hline Treatment & $\begin{array}{c}\text { Acartia } \\
\text { clausi }\end{array}$ & $\begin{array}{c}\text { Acartia } \\
\text { tonsa }\end{array}$ & $\begin{array}{c}\text { Eurytemora } \\
\text { herdmani }\end{array}$ & $\begin{array}{c}\text { Centropages } \\
\text { hamatus }\end{array}$ & $\begin{array}{l}\text { Oithona } \\
\text { similis }\end{array}$ \\
\hline \multicolumn{6}{|c|}{ Stratified top } \\
\hline Tank $1^{\hat{a}}$ & $15611 \pm 6246$ & $489 \pm 362$ & $638 \pm 221$ & $1982 \pm 2030$ & $89 \pm 47$ \\
\hline Tank 2 & $12660 \pm 4446$ & $5527 \pm 2360$ & $1976 \pm 1132$ & $3491 \pm 1289$ & $195 \pm 94$ \\
\hline \multicolumn{6}{|c|}{ Stratified bottom } \\
\hline Tank 1 & $20064 \pm 9389$ & $63 \pm 85$ & $2729 \pm 1592$ & $1655 \pm 1055$ & $23 \pm 19$ \\
\hline Tank 2 & $10672 \pm 2879$ & $35 \pm 23$ & $2923 \pm 1499$ & $1286 \pm 605$ & $49 \pm 47$ \\
\hline Bay & $86 \pm 38$ & $315 \pm 21$ & 0 & $260 \pm 368$ & $101 \pm 100$ \\
\hline \multicolumn{6}{|l|}{ Well-mixed } \\
\hline Control 1 & $1858 \pm 88$ & $2497 \pm 3000$ & $933 \pm 270$ & $1105 \pm 366$ & $1766 \pm 852$ \\
\hline Control 2 & $340 \pm 295$ & $2186 \pm 1955$ & $18 \pm 185$ & 0 & $188 \pm 221$ \\
\hline
\end{tabular}

The stratified system supported complex zooplankton communities that differed in several ways from the Bay and well-mixed mesocosms. Several of the major copepod species were enhanced relative to the Bay and well-mixed tanks in 1 or more layers of the stratified systems (Table 3). Acartia clausi (hudsonica), Eurytemora herdmani and Centropages hamatus all showed increased abundance relative to the Bay and in most cases to the well-mixed control mesocosms as well. The initial increase and high surface layer abundance of Acartia clausi were in contrast to those in well-mixed mesocosms and Narragansett Bay where A. clausi egg production and abundance delined above $18{ }^{\circ} \mathrm{C}$ and $A$. clausi was replaced by $A$. tonsa as the dominant copepod (Sullivan \& Ritacco 1985). It is not known whether $A$. clausi or the other herbivorous copepods were vertically migrating. The mechanisms underlying the high abundance and co-occurrance of so many presumably competing herbivorous copepods in the flagellate-dominated surface layer of the systems needs further study.

In addition to the increased abundances of presumably herbivorous copepods, the stratified system also supported a variety of predators including the ctenophore Pleurobrachea sp., the predatory copepod Tortanus discaudatus, and predatory larvae of the mud anemone Cereanthiopsis sp. Visual observations of the Pleurobrachea indicated that they were actively feeding based on both presence of food in their gut and repeated observations of tentacle retraction, a distinctive feeding behavior following capture of a prey. Pleurobrachea and the other predators were found in both top and bottom layers. The distribution of their feeding activity is unknown. The persistance of both large herbivore and predator populations in these systems is in contrast to the tendency for predator domi- nance in enclosures (Reeve 1980, Steel \& Henderson 1981, Steele \& Gamble 1982, Harris et al. 1982).

\section{Replication of planktonic community structure}

Throughout the above analysis of these systems, we have only discussed the response of a single system run in batch mode (no flow-through of sea water) and without any addition of pollutants. During this period, a second identical stratified mesocosm was run, but acid-iron waste was added and its fate defined over a period of several weeks (Fox \& Kester 1985). In the strict sense, data from this second mesocosm cannot be used to determine replicability of the stratified system. However, because (1) the concentration of the waste added was below levels expected to cause lethal effects (Capuzzo 1983), (2) the waste was rapidly lost from the water column (Fox \& Kester 1985, Fox et al. in press) and (3) analysis of trace metals in phytoplankton in dialysis sacks and zooplankton indicated little or no uptake (Fox et al. in press), some indication of replicability can be obtained by comparison of the 2 stratified mesocosms. A comparison of the vertical physical structure and phytoplankton community indicates that the 2 systems were very similar even after $56 \mathrm{~d}$ of operation (Fig. 7). Over shorter time scales, the abundances of flagellates were essentially identical between layers and between the 2 mesocosms (Fig. 8a). Diatom abundances were also very similar between replicate systems both at the community (Fig. $8 \mathrm{c}$ ) and species level (Fig. 8b, d). The slight difference in diatom abundances in the surface layer might have been the result of slightly lower silicate levels resulting from the stripping of silicate during waste flocculation. These differences were, however, at the limits of 


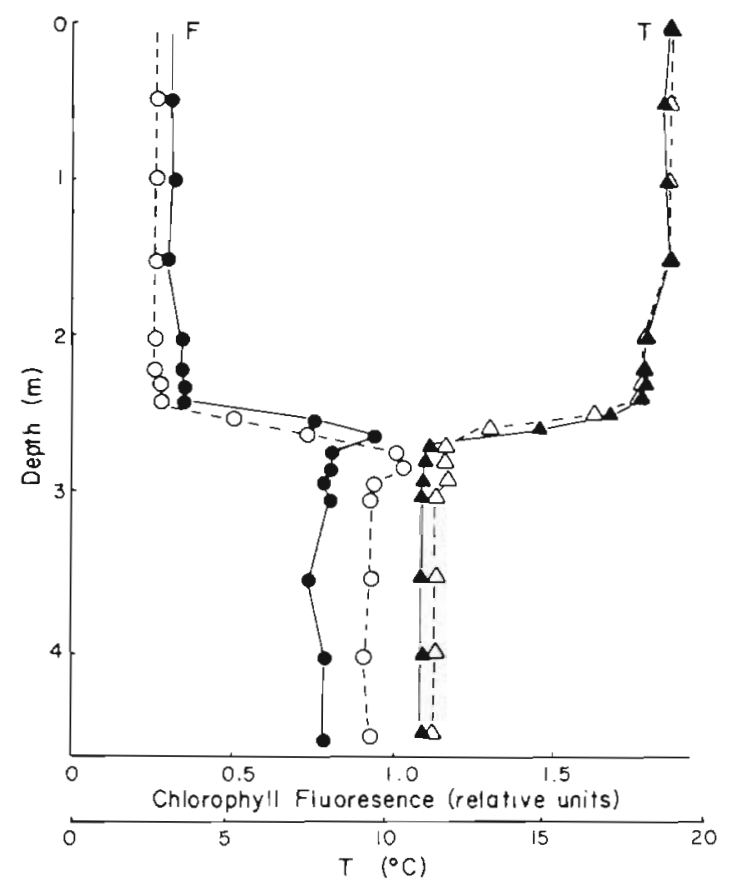

Fig. 7. Comparison of temperature (triangles) and fluorescence (circles) profiles from 2 stratified mesocosms after $56 \mathrm{~d}$ of operation. Solid symbols are for control tank and open symbols are for identical tanks to which acid-iron waste had been added $40 \mathrm{~d}$ earlier
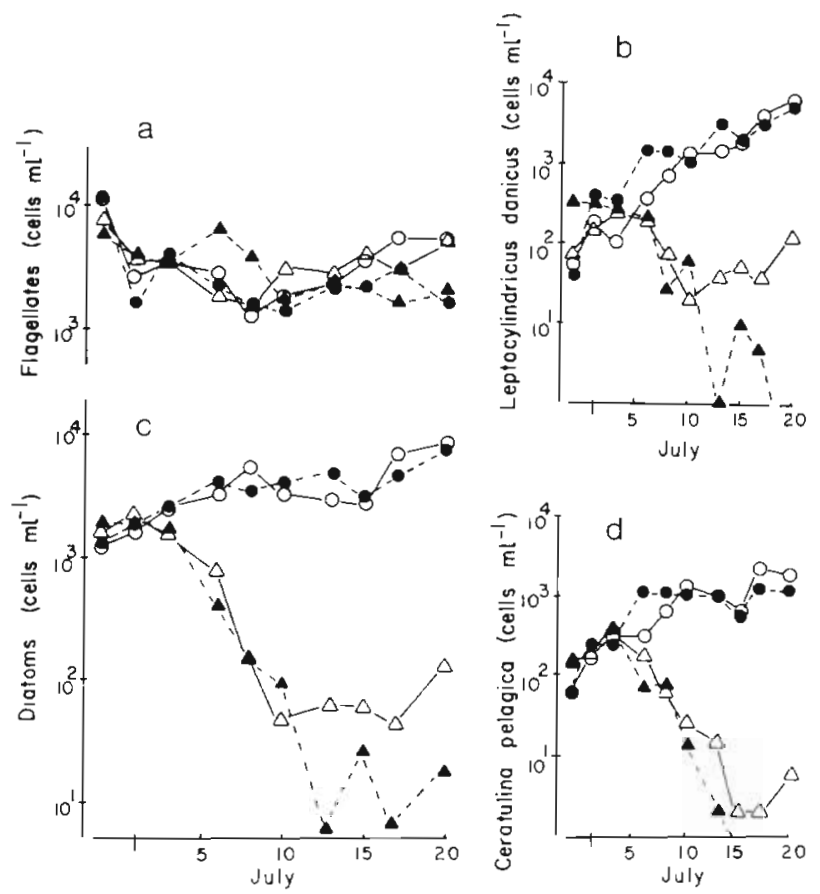

Fig. 8. Temporal variation in phytoplankton species composition in the top (triangles) and bottom (circles) layer of the 2 stratified mesocosms. Open symbols are for control mesocosms and solid symbols are for identical tanks to which acidiron waste had been added. Temporal variation is defined both for flagellates (a) and diatoms (c) as major groups of phytoplankton and for the 2 most abundant diatoms (b, d). Other less abundant diatoms (including Skeletonema costatum) showed similar patterns counting procedures. The absence of any net growth of Skeletonema costatum in the dialysis sacks in the surface layer of both systems indicated both systems were equally limited by macronutrient availability. The abundances and biomass of zooplankton were also similar between the 2 mesocosms (Table 3). The differences in abundance that were observed in Acartia tonsa were attributable to differences in initial populations of this species. In summary, the similarity of the planktonic populations in these 2 stratified mesocosms (despite the addition of waste to one of them) suggests that adequate replication might be expected in future use of these systems.

\section{DISCUSSION}

\section{Evaluation of stratified mesocosms as experimental systems}

Our initial objectives (Table 1) were met or exceeded by the modifications of the temperature and mixer control systems described above. As indicated by vertical profiles of physical, chemical and biotic variables, these modifications permitted development of stratified mesocosms composed of 2 well-mixed layers separated by a stable pycnocline. Manipulation of heat exchanger position, mixer speed, percent time mixer on, and mixer paddle spacing and design enabled development of a variety of vertical thermal structures and mixing regimes. The design of these systems allowed for considerable flexibility, and identical designs maintained similar vertical structure in replicate systems for $2 \mathrm{mo}$. When strong pycnoclines were established between 2 layers, strong chemical and biotic gradients rapidly developed and persisted. Both layers as well as the pycnocline region maintained viable planktonic communities containing at least 3 trophic levels including phytoplankton, herbivorous zooplankton and predators. The surface layers were characterized by very low nutrients, low phytoplankton biomass, and high zooplankton (proportional to phytoplankton). Wall fouling in the surface layer was minimal and easily controlled by brushing.

The mechanical mixing system used in these mesocosms had several advantages over the air bubbling mixer developed by Eppley et al. (1978). First, the mechanical mixing system allowed control of the vertical distribution of energy input not possible with air bubbling. Such control permitted a closer simulation of wind-induced energy input occurring in field systems. Second, mechanical mixing eliminated any potential effects of air bubbling on forming of particles from dissolved organics (Farrington 1983). Third, the mechanical mixing system allowed selective control of 
mixing in the bottom layer and control of mixing within and between layers. None of this is possible with air bubbling. The ability to control turbulence in the lower layer may be critical in the operation of stratified mesocosms containing a benthos since near bottom turbulence appears to be important to the functioning of benthic communities (Nixon et al. 1980, Donaghay 1984).

The ability to achieve very thin pycnoclines in addition to diffuse ones has several significant experimental advantages. First, it permits experimental testing of the ecosystem level effects of varying degrees of crossthermocline mixing covering the full range from very low rates dominated by diffusion processes to very high rates dominated by turbulent mixing. Second, such thin pycnocline experimental systems closely approximate important mathematical models composed of 2 well-mixed layers separated by a very thin pycnocline (Steele 1974, Evans 1978) and thus might facilitate testing of those models. Third, thin pycnocline systems have considerable sampling advantages. If a very high percentage of the total volume of the system is contained within 2 well-mixed layers, then samples from each of those well-mixed layers can be used to monitor and describe temporal changes in the system. Such a reduction in sampling effort is not a trivial concern in any experimental ecosystem. It must be noted, however, that for some substances, very important vertical microstructure can be defined in the pycnocline, and as a result sampling of this region cannot be completely avoided (Donaghay 1984). In those cases where structure within the pycnocline is of interest, it will be necessary to use non-destructive sampling techniques or to use stratified mesocosms of larger volume or with more diffuse pycnoclines. As has been discussed elsewhere (Banse 1982, Donaghay 1984), the suitability of any given mesocosm design may be as much dependent on experimental considerations such as those above as it is dependent on its approximation to any given field system.

\section{Comparison with field systems}

The chemical and biotic properties of the surface layer of these systems were in many ways similar to those observed in highly stratified field systems. The vertical uniformity in biotic and chemical parameters of the surface layer was similar to that of wind-mixed surface layers in the ocean. The low nutrient concentrations and input rates, the dominance of the phytoplankton by relatively low concentrations of flagellates, and the diverse zooplankton communities composed of both herbivores and predators were quite similar to the general conceptual models of highly stratified field systems (Steele 1974, Eppley et al. 1977, McCarthy \& Carpenter 1983). These characteristics would suggest that surface layer primary production processes in the stratified mesocosms were dominated, as in the field, by internal nutrient recycling, crossthermocline nutrient transport and zooplankton grazing. Preliminary observation of continuous grazing by surface layer zooplankton coupled with high ${ }^{14} \mathrm{C}$ based assimilation rates of phytoplankton production (Hitchcock unpubl.) suggest high turnover rates in the surface layer. The lack of cell growth in Skeletonema costatum placed in dialysis sacks in the surface layer coupled with $\mathrm{SiO}_{4}$ concentrations shown to limit growth in laboratory cultures (Paasche 1973) suggest that growth of this initially important diatom was nutrient limited. ( $S$. costatum was the third most abundant diatom in the initial surface layer diatom bloom.) Whether flagellate growth rates were similarly nutrient limited is not known. Unfortunately, we do not know the rates of primary and secondary production in the tanks and how they would compare to rates in natural systems. The large copepod populations seemed to thrive on moderate flagellate populations much as observed by Holligan et al. (1984) in stratified field systems. Direct measurements of the processes coupling phytoplankton and zooplankton in stratified mesocosms will surely help in development of a consensus of how to measure them in the field (see reviews by Eppley 1980, Goldman 1980, McCarthy \& Carpenter 1983). The high degree of replicability and temporal constancy of populations of phytoplankton and zooplankton in the surface layers suggest that a dynamic equilibrium or steady state has been achieved in these mesocosms, much as is thought to exist in central ocean gyres (Eppley 1980) and in some highly stratified coastal waters (Holligan et al. 1984).

The pycnocline and bottom layers of the thermohaline stratified mesocosms were more similar to those in highly stratified coastal systems than to those in open ocean systems. Although not a requirement of the stratified mesocosm design (see Fig. 3a to d), the pycnocline in the strongly stratified thermohaline system (Fig. 3d) was much more compressed than that often observed in open ocean areas where thermoclines of $10 \mathrm{C}^{\circ}$ are normally spread over meters rather than tens of centimeters. In deep water systems these wide pycnoclines tend to have associated chlorophyll a maxima (e.g. Cullen \& Renger 1979; see Jumart et al. 1977 for review and model) much as observed in the more weakly stratified mesocosm (Fig. 3b). Despite the more general open ocean tendency for broad thermoclines, very sharp thermoclines can exist in coastal environments. In some cases these pycnolines are not associated with strong chloropyhall a maxima. Rather, chlorophyll a maxima occur in bottom layers (Holligan 
\& Harbour 1977, Motoda et al. 1978). Bottom layer chlorophyll a maxima occur in shallow-water field systems where light penetrates to the bottom layer allowing some production (Motoda et al. 1978) and where tidal mixing of the bottom layer tends to maintain diatoms in suspension (Holligan \& Harbour 1977). These same processes are almost certainly important in controlling the battom layer diatom populations and primary production processes in the thermohaline stratified mesocosm described here.

Studies of mixing in enclosures have consistently supported the hypothesis that mixing within and between layers of stratified marine ecosystems plays an important role in controlling their dynamics and composition. Steele et al. (1977) demonstrated that enclosure of naturally stratified water column reduced the turbulence level by a factor of more than 100, and as a result vertical mixing and physical structure rapidly diverged from that in surrounding waters. Subsequent comparisons of air-bubble mixed and unmixed surface layers in these systems (Eppley et al. 1978) demonstrated that some level of turbulence was essential to maintain diatoms. Comparison of mixed and unmixed mesocosms (Oviatt 1981), stratified and well-mixed mesocosms (this work), and mixed and stratified field systems (Holligan et al. 1984) have indicated that mixing can alter the dynamics and composition of whole ecosystems as well as that of individual trophic levels. Given this evidence for the importance of mixing, it is our conclusion that more attention needs to be directed at testing the role of mixing in controlling ecosystem composition and dynamics. Since there is evidence that both turbulence within a layer as well as mixing between layers can affect ecosystem composition and dynamics, future studies must begin to separate and experimentally test the relative significance of each of these factors. Such studies should enhance our understanding of the effects of mixing and spatial heterogenity on marine ecosystems and lead to the development of mesocosms that more accurately simulate stratified field environments.

Acknowledgements. This work was supported as part of a National Oceanic and Atmospheric Administration Grant \#NA79-AA-D-00033 to Drs. Kester and Fox for testing the effect of vertical stratification on the fate of acid-iron industrial wastes. We also thank Drs M. E. Q. Pilson, C. A. Oviatt, and C. D. Hunt for their contributions to this work. Editorial comments by Dana Kester, Victor Smetacek, Mary Fox, Carlton Hunt, Candace Oviatt and the reviewers are deeply appreciated.

\section{LITERATURE CITED}

Banse, K. (1982). Experimental marine ecosystems enclosure in a historical perspective. In: Grice, G. D., Reeve, M. R. (ed.) Marine mesocosms. Springer-Verlag, New York, p. $11-24$

Capuzzo, J. M. (1983). The role of zooplankton in accumulation and deposition of DuPont Edgemoor waste (an acidiron wate) at Deepwater Dumpsite in the Northwest Atlantic. J. Fish Res. Bd Can. 40 (Suppl. No. 2), p. 242-247

Cullen, J. H., Renger, E. H. (1979). Continous measurement of DCMU induced fluorescence response of natural phytoplankton populations. Mar. Biol. 53: 13-20

Donaghay, P. (1984). Utility of mesocosms to assess marine pollution. In: White, $H$. (ed.) Concepts in marine pollution. Maryland Sea Grant Program, College Park, Maryland, p. 589-620

Eppley, R. W (1980). Estimating phytoplankton growth rates in the central oligotrophic oceans. In: Falkowski, P. G. (ed.) Primary productivity in the sea. Plenum Press, New York, p. 231-242

Eppley, R. W., Sharp, J. H., Renger, E. H., Perry, M. J., Harrison, W. G. (1977). Nitrogen assimilation by phytoplankton and other microorganisms in the surface waters of the Central North Pacific Ocean. Mar. Biol. 39: 111-120

Eppley, R. W., Koeller, P., Wallance, G. T. (1978). Stirring influences the phytoplankton species composition within enclosed columns of coastal water. J. exp. mar. Biol. Ecol. 32: $219-239$

Evans, G. T (1978). Biological effects of vertical-horizontal interactions. In: Steele, J. H. (ed.) Spatial patterns in plankton communities. Plenum Press, New York, p. 131-156

Farrington, J. W. (1983). Biogeochemistry of microaggregate organic matter: a review and speculation. EOS Trans. Am. geophys. Un. 64 (52): 1019

Fox, M. F., Kester, D. R. (1985). Fate of ocean dumped acidiron waste in a MERL stratified mesocosm. In: Duedall, I. W., Ketchum, B. H. Park, P. K., Kester, D. R. (ed.) Wastes in the ocean. Wiley-Interscience, New York, p. 171-185

Fox, M. F., Kester, D. R., Hunt, C. D. (in press). Vertical transport processes of acid-iron waste in a MERL stratified mesocosm. Environ. Sci. Technol.

Friederich, G. O., Whitledge, T. (1972). Autoanalyser procedures for nutrients, In: Pavlou, S. D. (ed.) Chemostat methodology and chemical analyses. Spec. Rep. 52, Dept. Oceanogr., Univ. of Wash., Seattle, p. 38-60

Goldman, J. C. (1980). Physiological processes, nutrient availability, and the concept of relative growth rate in marine phytoplankton ecology. In: Falkowski, P. C. (ed.) Primary productivity in the sea. Plenum Press, New York, p. 179-194

Guillard, R. R. L. (1978). Counting slides. In: Sournia, A. (ed.) Phytoplankton manual. UNESCO, Paris, p. 182-189

Harris, R. P., Reeve, M. R., Grice, G. D., Evans, G. T., Gibson, V. R., Beers, J. R., Sullivan, B. K. (1982). Trophic interactions and production processes in natural zooplankton communities in enclosed water columns. In: Grice, G. D., Reeve, M. R. (ed.) Marine mesocosms. Springer-Verlag, New York, p. 355-388

Holligan, P. M., Harbour, D. S. (1977). The vertical distribution and succession of phytoplankton in the western English Channel in 1975 and 1976. J. mar. Biol. Assoc. U. K. 57: 1075-1093

Holligan, P. M., Harris, R. P., Newall, R. C., Harbour, P. S. Head, R. N., Linley, E. A. S., Lucas, M. I., Tranter, P. R. G., Weekley, C. M. (1984). Vertical distribution and partitioning of organic carbon in mixed, frontal and stratified waters of the English Channel. Mar Ecol. Prog. Ser. 14: $111-127$

Jumart, B. M., Winter, D. F., Banse, K., Anderson, G. E., Lam, 
R. K. (1977). A theoretical study of phytoplankton growth and nutrient distribution in the Pacific Ocean off the northwestern U. S. coast. Deep Sea Res. 24: 753-773

Kullenberg, G. E. B. (1978). Vertical processes and vertical horizontal coupling. In: Steele, J. H. (ed.) Spatial pattern in plankton communities. New York, Plenum Press, p. $43-71$

Lorenzen, C. J. (1966). A method for continuous measurement of in vivo chlorophyll concentration. Deep Sea Res. 13: $223-227$

Margalef, R. (1978). Life forms of phytoplankton as survival alternatives in an unstable environment. Oceanologica Acta 1: 493-509

McCarthy, J. J., Carpenter, E. J. (1983). Nitrogen cycling in near-surface waters of the open ocean. In: Carpenter, E. J., Capone, D. C. (ed.) Nitrogen in the marine environment. Academic Press, New York, p. 487-572

Motoda, S., Kawamura, T., Taniguchi, A. (1978). Differences in productivities between the Great Australian Bight and the Gulf of Carpentaria, Australia, in summer. Mar. Biol 46: 93-99

Nixon, S. W., Alonso, D., Pilson, M. E. Q., Buckley, B. A. (1980). Turbulent mixing in aquatic microcosms. In: Giesy, J. P. (ed.) Microcosms in ecological research. DOE Symp. Ser, Augusta, Georgia, p. 818-849

Nixon, S. W., Pilson, M. E. Q., Oviatt, C. A., Donaghay, P. L., Sullivan, B., Seitzinger, S., Rudnick, D., Frithsen, J. (1984). Eutrophication of a coastal marine ecosystem - an experimental study using the MERL microcosms. In: Fasham, $M$ (ed.) Flows of energy and materials in marine ecosystems: theory and practice. Plenum Press, London, p. 105-135

Oviatt, C. A. (1981). Effects of different mixing schedules on phytoplankton, zooplankton and nutrients in marine microcosms. Mar. Ecol. Prog. Ser. 4: 57-67

Oviatt, C. A., Frithsen, J., Gearing, J., Gearing, P. (1982). Low chronic additions of no. 2 fuel oil: chemical behaviour, biological impact and recovery in a simulated estuarine environment. Mar. Ecol. Prog. Ser. 9: 121-136

Paasche, E. (1973). Silicon and the ecology of marine plank- ton diatoms. I. Thalassiosira pseudonana (Cyclotella nana) grown in a chemostat with silicate as the limiting nutrient. Mar Biol. 19: 117-126

Pilson, M. E. Q., Nixon, S. W (1980). Marine microcosms in ecological research. In: Giesy, J. P. (ed.) Micorcosms in ecological research. DOE Symp. Ser. Augusta, Georgia, p. $724-741$

Reeve, M. R. (1980). Population dynamics of ctenophores in large scale enclosures over several years. In: Smith, D. C., Tiffon, $Y$ (ed.) Nutrition in the lower Metazoa. Pergamon Press, New York, p. 73-86

Santschi, P. H. (1982). Application of enclosures to the study of ocean chemistry. In: Grice, G. D., Reeve, M. R. (ed.) Marine mesocosms: biological and chemical research in experimental ecosystems. Springer Verlag, New York, p. $63-80$

Steele, J. H. (1974). The structure of marine ecosystems. Harvard Univ, Press, Cambridge, Massachusetts

Steele, J. H., Gamble, J. C. (1982). Predation control in enclosures. In: Grace, G. D., Reeve, H. R. (ed.) Marine mesocosms. Springer Verlag, New York, p. 227-238

Steele, J. H., Henderson, E. W. (1981). A simple plankton model. Am. Nat. 117: 676-691

Steele, J. H., Farmer, D. M., Henderson, E. W. (1977). Circulation and temperature structure in large marine enclosures. J. Fish. Res. Bd Can. 34: 1095-1104

Strickland, J. D. H., Parsons, T. R. (1968). A practical handbook of seawater analysis. Bull. Fish. Res. Bd Can. 167

Sullivan, B. K., Ritacco, P. J. (1985). The response of the dominant copepod species to food limitation in a coastal marine ecosystem. Arch. Hydrobiol. Beih. Ergeb. Limnol. 20

Venrick, E. L. (1978a). Implications of subsampling. In: Sournia, A. (ed.) Phytoplankton manual. UNESCO, Paris, p. $75-87$

Venrick, E. L. (1978b). How many cells to count? In: Sournia, A. (ed.) Phytoplankton manual. UNESCO, Paris, p. $176-180$ 